\title{
Study of the Characteristics and Practice Guidance of Girls Sports Teaching
}

\author{
Cairong $\mathrm{Wu}^{1, \mathrm{a}}$, Jie Deng ${ }^{2, \mathrm{~b}}$ \\ 1,a Zhengde Polytechnic College, Nanjing, 211100, China \\ 2,b Nanjing University OF Aeronautics And Astronautics, Nanjing, 210016, China \\ a, cairongwu2013@yeah.net
}

Keywords: Girls; Sports teaching; Guidance and practice; Linear regression; Level coefficient

\begin{abstract}
Physical education is one of the important modules of comprehensively cultivating the comprehensive talents of quality education. Aiming at the research for girls' sports teaching has increased year by year, and it indirectly reflects that the status of the girls' sports teaching in physical education has been constantly risen. Girls' sports teaching research is a hot topic in the current research field. This paper firstly makes summative elaboration on the cognitive status of the girls' sports education based on the investigation. On this basis, it applies interval significant level regression coefficient to judgment to analyze the main influencing factors of girls' sports teaching. Based on the linear regression model, it further builds the optimized guidance model of girls' sports teaching practice. From the perspective of girls' sports teaching practice, it emphasizes the purpose and importance of girls' sports teaching on sports teaching work, which provides theoretical support and practical guidance for the study of the girls' sports teaching.
\end{abstract}

\section{Introduction}

Sports teaching are an important part of college daily education. Through the understanding and practice of sports teaching, it enables students to establish a good physical and psychological quality, and cultivate the courage to forge ahead, resilient striving spirit [1,2]. In the study of girls' sports education teaching, many experts and scholars and teachers summarize past practical experience, and put forward their own unique theory point of view. In the teaching practice of college sports teaching, girls' sports teaching has always been a relatively weak part of sports teaching [3]. How to make full use of girls' sports teaching function, it is the urgent to be solved problem in the optimization of girls' sports teaching practical methods. With the rapid development of China's economic level, education level is also rising. Sports teaching have been showing a trend of diversified development, gradually refined to the factor of age, gender, physical fitness of students. In order to cultivate students to pay attention to their health and physical exercise consciousness, it needs to carry out targeted teaching mode, build a complete framework of China's physical education, so as to provide a reliable guarantee for the early realization of the high quality of the sports teaching goal. According to many reasons that girls are lack of correct understanding on sports teaching, they can't adapt to the teaching environment, they are afraid of teaching of sports teaching from the psychology, their physical quality is difficult to be promoted by practice [4-6]. University education is a critical stage to acquire knowledge and skills in life. It is a very critical part that evaluating the university sports' teaching, and this is a good standard to measure the quality of teaching.It could constantly find the lack of PE teaching and make it improved so that there is better arrangement of the university sports' teaching. On the university sports teaching, many are still from a single way to carry on the teaching now, and the evaluation mode is limited to the category of the general PE teaching's content.How can we provide the quality of university sports' teaching and how to teach sports effectively,which is worthwhile everyone think deeply.All this reasons, make girls' awareness is superficial on sports teaching, and lack of interest. In today's physical education reform and development under the background of current reformed sports teaching development, it advocates healthy athletics teaching philosophy. College girls sports teaching should also adapt to the new situation, and scientifically and effectively cultivate girls to gradually form correct physical value and the basic sports consciousness of lifelong training.

\section{Girls cognitive status of sports teaching}


Since the end of feudal society, and the founding of new China, equality between men and women in China tends to be more and more scientific. Women's proportion of participating in national and social affairs has largely increased. Girls' sports teaching is also the core part of curriculum system in the whole process of sports teaching. It effectively plays girls' unique features by sports teaching. Sports teaching are assimilated into the full development of girl students, which effectively makes full use of the active promotion role of sports teaching in the girls growing. In order to make a better and scientific analysis on the characteristics and practical guidance of girls' sports teaching, we carry out open questionnaire survey on college girl students of different grades in different areas, which is mainly related to the three aspects of personal cognitive status of sports teaching for girls.The investigation involves with girls' personal interest, the value of teaching content, and sports motivation in sports teaching. The proportion of girls who are very interested in sports teaching is relatively small. Different grades students who are interested in sports teaching that the ratio is around $10 \%$. The ratio of students are not clear, they are about $50 \%$ and students who have no interested account for $30 \%$.

Girls think that sports teaching value is very important that the proportion is relatively small. Different grades students feel the value of sports teaching value is important that the proportion is about $20 \%$. The students who are not clear that in the ratio is about $50 \%$, and the proportion of no importance students accounts for $30 \%$.

In the following investigation of learning motivation in girl sports, we find girls learning motivation is not clear enough. Most of the students are for the credit to choose the physical education, and some only want to spend their time, which are not conducive to personal development. About $80 \%$ of the students think that their learning sports are to obtain credit, and even to pass the time.

For different grades' students, the main cause of most students' learning sports teaching is to obtain credit and to pass the time. The proportion of enhancing their overall quality is very small.

Table 1 and Table 2, and Tab.3 are to make statistics and summarized. It is not difficult to find the existence of the common link between two. Girls' interest in sports teaching is close to $50 \%$. There are also $50 \%$ of the students for the value cognition of sports teaching is vague. Female students' interest and value cognition for sports teaching are both relatively low.

\section{Characteristics of girls' sports teaching and main influent factors analysis}

Education modernization demands the compulsory education to be diversified development. And sports teaching also presents the trend of diversified development, gradually refine into age, gender, physical and other factors. It implements targeted scientific teaching model to cultivate students to pay attention to their own health and consciousness of participating in the physical training, which can reach the goal of high quality sports teaching, and provide a reliable guarantee for citizen health system.

Girls' sports teaching are the difficulties in the current sports teaching. From the integrated view of girls' sports teaching, its special features are as shown below.

In the whole girls' sports teaching, the cognition of sports teaching value for girls is the main influence factors for the entire teaching, so in the teaching process, sports workers need to strengthen girls' cognition of the sports teaching value, improve the sports ability, create and maintain the good habit of physical exercise. It should be based on improving physical quality and health level to establish a more self-confident, self-improvement and self-love innovation and pioneering spirit.

\section{Construction of optimized girls' sports teaching practice and guidance model}

Girls' sports teaching process should follow the basic theory of modern physical education. From the four steps that the dissemination and exploration of knowledge, cultivate ability, form a good character, and grasp scientific and effective learning methods, it gradually carries out infiltration education for students. 
Sports teaching makes students from the knowledge, ability, character and methods be assimilated into the practical teaching, so as to improve the acceptance and consciousness of sports teaching for girls, which should depend on reasonable teaching methods, scientific teaching means and strong sports classroom atmosphere to attract students, arouse the enthusiasm of girls in the course. The influence factors random variable of girls' sports teaching is set as $Y$, and the sample observations are $Y_{i},(i=1,2, \cdots, n)$. In girls' sports teaching practical guidelines, it through variance analysis, carries out scientific and effective guidance for the parts which can or can't use $X$ or sample regression line $\hat{Y}=\hat{\beta}_{1}+\hat{\beta}_{2} X_{2 i}$ to illustrate in the entire $Y_{\text {variation. }}$

so:

$Y-\bar{Y}=(\hat{Y}+\hat{u})-\bar{Y}=(\hat{Y}-\bar{Y})+\hat{u}$

Square on both sides:

$$
(Y-\bar{Y})^{2}=[(\hat{Y}+\hat{u})-\bar{Y}]^{2}=[(\hat{Y}-\bar{Y})+\hat{u}]^{2}=(\hat{Y}-\bar{Y})^{2}+\hat{u}^{2}+2 \hat{u}(\hat{Y}-\bar{Y})
$$

Summation:

$$
\sum(Y-\bar{Y})^{2}=\sum(\hat{Y}-\bar{Y})^{2}+\sum \hat{u}^{2}+2 \sum \hat{u}(\hat{Y}-\bar{Y})=\sum(\hat{Y}-\bar{Y})^{2}+\sum \hat{u}^{2}
$$

So:
$\sum(Y-\bar{Y})^{2}=\sum(\hat{Y}-\bar{Y})^{2}+\sum \hat{u}^{2}$

The left in the formula represents the sum of deviation squares about variable sample values related to its average. Creating a relaxed and interested classroom atmosphere is the basis of developing education and teaching, which can not only destroy the characteristics of students, denoted by SST; also can't kill the students desire for knowledge, at the same time, should fuse the important thought of physical education into the whole course, denoted by SSR. When students are acquiring new knowledge, it also needs to have independent thinking and thinking space and freely play space, denoted by SSE. Providing creative platform for students is the priority among priorities to improve students' understanding of knowledge and grasping ability, is also the good opportunity to cultivate students to learn in order to practice, infer other things from one fact. It should try to avoid phenomenon that students blindly receive knowledge, mechanically practice. The total sum of squares is equal to the sum of squares and the residual sum of squares.

$\mathrm{SST}=\mathrm{SSR}+\mathrm{SSE}$

For the sum of regression square, a formula is established.

$$
\mathrm{SSR}=\sum(\hat{Y}-\bar{Y})^{2}=\sum\left[\left(\hat{\beta}_{1}+\hat{\beta}_{2} X_{2 i}\right)-\left(\overline{\left.\hat{\beta}_{1}+\hat{\beta}_{2} X_{2 i}\right)}\right]^{2}\right.
$$

So:

$$
\begin{aligned}
& \mathrm{SSR}=\hat{\beta}_{2}{ }^{2} \sum x_{2 i}{ }^{2} \\
& \mathrm{SSR}=\hat{\beta}_{2}{ }^{2} \sum x_{2 i}{ }^{2}+\sum \hat{u}_{i}{ }^{2}
\end{aligned}
$$

By formula (14), (15), it obtains the sports teaching project is only the carrier of practical teaching. In order to do the basic work of sports teaching, and realize the teaching goal, it fundamentally lies in the reasonable use of teaching methods to enrich the content of teaching practice, and carry out the diversity of physical education teaching activities, which changes the relationship among the teaching factors of girls' sports teaching from the form. The total variation can be represented by a diagram, and it is shown in Figure 4. 


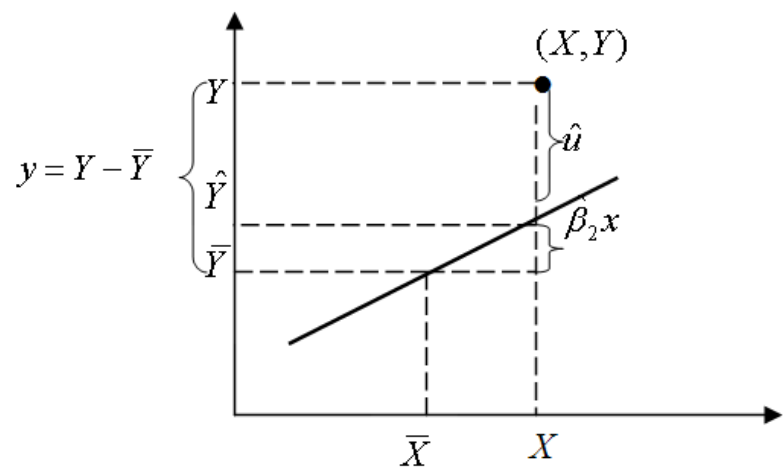

Figure 1. Model of optimized girls' sports teaching practice and guidance

Figure 1 is the model of optimized girls' sports teaching practice and guidance. Girls' sports teaching should focus on the deeper understanding of female sports teaching control the overall thought of sports teaching, so as to clear the essence of sports teaching to accurately achieve the long-term goal of teaching.

Blending the theory of multiple intelligences into the university sports' teaching, which not only makes sports' teaching more colorful for students, also leads schools and teachers to create a good atmosphere more actively so that students are allowed to actively take in the university sports' teaching, and it mobilizes the students ' subjective activeness adequately. Moreover,for the tests' results of the students' PE, or even each element of the multiple intelligence also has a great deal of promotion, so it is effective to use the theory of multiple intelligence in university sports' teaching.And we should strengthen the application of it in teaching and find more appropriate and effective methods to achieve students' full development constantly, which also makes the activities of teaching and learning be efficient and in perfect order.

\section{Conclusion}

Under the big background of China's education system reformed and the health level of citizens improved, sports teaching had be more and more paid attention from all aspects. Solving the possible existing complex problems in sports teaching, and smoothing the obstacles in daily sports teaching are the important links to improve sports teaching quality. Characteristic analysis and practice research of girls' sports teaching is fully to implement the health humanities idea of sports teaching, so as to cultivate new generation outstanding women with innovative ability, physical and mental development, and strong quality adapting to the needs of the times.

\section{References}

[1] Machar Reid, Knut Schneiker, "Strength and conditioning in tennis: Current research and practice", Neuroscience, Vol. 11, No. 3, pp. 248-256, 2008.

[2] Fang Ya, "The Modeling on Sports Videos based on Bayesian network and Feature Maps", IJACT, Vol. 4, No. 22, pp. 692 -608, 2012.

[3] Sarit Freimann, Mickey Scheinowitz, "Prior exercise training improves the outcome of acute myocardial infarction in the rat: Heart structure, function, and gene expression", Journal of the American College of Cardiology, Vol. 45, No. 6, pp. 931-938, 2005.

[4] Jonathon P.R. Scott, Lars R. McNaughton, "Effects of sleep deprivation and exercise on cognitive, motor performance and mood", Physiology \& Behavior, Vol. 87, No. 2, pp. 396-408, 2006.

[5] Tiffany Field, "Exercise research on children and adolescents", Complementary Therapies in Clinical Practice, Vol. 18, No. 1, pp. 54-59, 2012.

[6] Su Rui, Xun Ma, "The Impact of Title Event Sponsorship Announcements on Enterprise incomings Based on Background of China", AISS, Vol. 4, No. 19, pp. 438-442, 2012 